4 The author (Theodore Roszak) belongs to the libertarian Left rather than with the adherents of deep ecology, but his argument at this point is close to it.

5 Frederick Engels, Dialectics of Nature [wr. 1873-6, pub. 1925, trans. Clemens Dutt 1940]. This particular passage from Engels' fragment dates from 1876, hence follows on the heels of John Ruskin's environmental and social turn in the 1870s, starting with Letter V of Fors Clavigera (1871). Engels also discusses Ernst Haeckel's Generelle Morphologie der Organismen (1866), in which the term 'ecology' makes its first appearance. Williams refers to Dialectics of Nature in 'Problems of Materialism' in his Problems in Materialism and Culture (Williams 1980c: 110-11), as well as in 'Socialism and ecology' (Williams [1982] 1989i: 214).

See also Francis Mulhern's review essay of the book 'Towards 2000, or news from you-know-where': Mulhern 1989, esp. 79-81.

7 'Socialism and ecology' (1982), reprinted in Raymond Williams, Resources of Hope: Culture, Democracy, Socialism, ed. Robin Gable (Williams [1982] 1989i).

8 A case in point is the current push towards biofuels in countries such as Indonesia, Malaysia and Brazil, engineered by giant transnational agro-companies in the interest of the energy-consuming economies of the West, but at the cost of price increases in food in the local economies and grave environmental risks. See Eric Holt-Giménez, 'Sprit vom Acker: Fünf Mythen vom Übergang zu Biokraftstoffen', Le Monde diplomatique (German edition), June 2007, pp. 12-13. The food riots in Egypt and Haiti in 2008, while linked more generally to the implementation of neo-liberal policies, may be taken as the first warning signs of greater disasters to come.

9 For a more extended treatment of the novel, see my essay 'Material grounds: border and place in Raymond Williams's fiction' (Klaus 2002).

10 More as translated by Ralph Robinson (1551): 'shepe that were wont to be so meek and tame and so smal eaters, now, as I heare saye, be become so great devowerers and so wylde, that they eate up, and swallow downe the very men them selfes' (Book I of Utopia), quoted from the Everyman edition (More 1910: 23).

11 'Remembrances' (c. 1832). Williams' continual interest in Clare is illustrated by his and his daughter's collection of the poet's writings, John Clare: Selected Poetry and Prose, eds. Merryn Williams and Raymond Williams (London: Methuen, 1986).

12 This and the next Williams paragraph open both volumes of People of the Black Mountains.

13 For a short incisive reading of People of the Black Mountains see Head 2002a: 197-9; see also Head's in part identical essay 'Beyond 2000: Raymond Williams and the ecocritic's task' (Head 2002b).

14 This treatment combined with the move to nurture and reproduction in Towards 2000 goes some way towards meeting the feminist critiques levelled against Williams' work and summed up in Morag Shiach's essay 'A gendered history of cultural categories' (Shiach 1995).

\section{Cultural studies is ordinary}

Gilbert B. Rodman
If this is thought through now, if we fight for it, even if we fail we shall have done something to justify ourselves before the future. But I don't think we need fail at all; I think the results will be uneven and scattered, but this is where the challenge now is. If you accept my definition that this is really what Cultural Studies has been about, of taking the best we can in intellectual work and going with it in this very open way to confront people for whom it is not a way of life, for whom it is not in any probability a job, but for whom it is a matter of their own intellectual interest, their own understanding of the pressures on them, pressures of every kind, from the most personal to the most broadly political - if we are prepared to take that kind of work and to revise the syllabus and discipline as best we can, on this site which allows that kind of interchange, then Cultural Studies has a very remarkable future indeed.

(Williams, 1989c: 161-2)

Cultural studies is ordinary: that is where we must start. More crucially, that is where we must finish. Understood one way, my refashioning of one of Raymond Williams' most famous titles describes the nature of cultural studies' current malaise: its transformation from what was once an extraordinary approach to intellectual and political work into something predictable and boring. Inflected a different way, however, 'cultural studies is ordinary' stands as a deliberate provocation: a polemical attempt to jolt us out of our limited understanding of what cultural studies is, where it can be found, and who actually does it.

When Williams wrote 'Culture is ordinary' half a century ago, he was trying to promote a more expansive and democratic understanding of what counts as culture. Rejecting the pervasive notion that culture is something possessed only by educated highbrows, Williams insisted that culture is a phenomenon common to all people, regardless of their position in the social hierarchy. A truly democratic society, Williams argued, cannot be built around the elitist assumption that 'the masses' possess nothing more 
than a watered-down version of 'real' culture - or, even worse, that they lack culture completely. In fact, the very notion of 'the masses' was foreign to Williams' project. 'There are ... no masses,' he insisted, 'but only ways of seeing people as masses' (Williams [1958] 1989b: 11).

Though Williams is often acknowledged to be one of cultural studies' foundational figures - and though his writings continue to be cited and taught in cultural studies circles - the radically democratic vision of culture and politics that characterized his work is surprisingly difficult to find in most contemporary formations of the enterprise. This is not to say that cultural studies no longer values democracy but that, on the whole, cultura studies has distanced itself from the broader public that it ostensibly struggles alongside. While there are numerous definitions of cultural studies in circulation - with an astonishing amount of variation between them - most of these competing maps of the territory share the fundamental assumption that cultural studies is necessarily an academic endeavour.

On the face of it, cultural studies' entrenched position in the university would seem to place it well outside the range of human activity that might typically be considered 'ordinary', especially when one considers the ten dency of cultural studies scholars to brandish theoretical abstractions and disciplinary jargon as if they were lethal weapons. Concepts such as 'affec tive alliances' and 'hegemonic blocs' may be useful tools for helping to make sense of the complicated interweavings of culture and politics, but they also build imposing fences around cultural studies that keep 'ordinary' people on the outside looking in - or, more likely, alienated enough from the whole affair that they find something more palatable to look at. To be sure, Williams often produced his own dense thickets of scholarly prose, and he was certainly happy to see cultural studies win a small measure of space for itself within the university. But neither the 'astonish[ing] ... theoretical fluency' (Hall 1992: 286) that has come to characterize much of cultural studies nor the gradual but steady sedimentation of cultural studie into a discipline of its own are quite the direction that Williams wanted the enterprise to take.

Williams' hopes for cultural studies' future were based largely on its prior efforts to use the concerns of 'ordinary people' as a set of guidelines for reshaping the dominant institutional practices of education and criticism. More specifically, Williams wanted cultural studies to avoid repeating the mistakes that English studies had made in moving from the fringes of British academic life to a position at the very heart of the beast. For Williams, that move had proven to be a Faustian bargain, in which the original endeavour ultimately traded away the noble democratic impulses at its core for the acquiescent stability provided by formal disciplinarity:

Having got into the university, English studies had within twenty years converted itself into a fairly normal academic course, marginalizing those members of itself who were sustaining the original project. Because by this time what it was doing within the institution was largely reproducing itself, which all academic institutions tend to do: it was reproducing the instructors and the examiners who were reproducing people like themselves. Given the absence of that pressure and that demand from groups who were outside the established educational system, this new discipline turned very much in on itself. It became, with some notable advantages, as always happens, a professional discipline; it moved to higher standards of critical rigour and scholarship; but at the same time the people who understood the original project ... were marginalized.

(Williams 1989c: 153)

Unfortunately, Williams' warning fell on deaf ears. Or perhaps it simply came too late. Change but a single word in the first line - 'English' to 'cultural' - and this passage is an uncannily prescient description of what has happened to cultural studies in the two decades since Williams' death.

In that time span, cultural studies has grown increasingly (and disturbingly) comfortable with the idea that it has matured into a discipline of its own. In spite of the lessons it should have learned from its contentious past, cultural studies has managed to acquire an unusually settled sense of its own history - and, even worse, of its own future. It is in this sense that cultural studies has become ordinary: just another undergraduate major, just another academic career choice, just another cog in the university's disciplinary machinery. And so it's not surprising (though it is disappoint ing) that the benchmarks for cultural studies' success are now more often about reproduction than about invention, more about finding one's place within the system than about remaking that system in significant ways or forging new paths for intellectual and political work.

One of the most obvious signs of this shift is the dramatic proliferation of cultural studies textbooks. It wasn't that long ago that the generic 'What is cultural studies?' publication was a 20-30 page essay that was as prescriptive in its focus ('this is what cultural studies should be') as it was descriptive ('this is what cultural studies is'). John Storey's (1996) marvellous anthology, What Is Cultural Studies?, gathers together nearly two dozen of these essays, and except for the couple that focus on the history of the Birmingham Centre ('this is what cultural studies was'), all of them define cultural studies in ways that suggest a future very much in flux. These essays can be understood as vectors: definitions in motion that aim to map out an ideal future direction for cultural studies as much as they attempt to describe the existing state of the terrain.

By way of contrast, the standard 'what is cultural studies?' publication today is a $200-300$ page introductory textbook aimed at undergraduates. As mutually incompatible as individual titles in this rapidly expanding genre 
often are, what they generally have in common is the sense that cultural studies is already an established discipline. In these volumes, if the future of the endeavour comes into play, it almost never does so in ways that suggest that cultural studies could (or should) deviate significantly from where it is right now. That future depends on how well cultural studies students can build professional academic careers around the blueprints provided by their forebears - and so presumably that future will look an awful lot like the present. Whatever these books are - and not all of them actually deserve to be thought of as 'cultural studies' - they're certainly not vectors: they're still lifes that provide a survey of cultural studies' 'greatest hits', capture them in amber, and then repackage them for mass consumption and further reproduction.

Textbooks are but one example of cultural studies' increasingly settled status as an ordinary academic enterprise. Cultural studies has now embraced virtually all the major trappings of scholarly professionalization: undergraduate majors, university departments, research centres, scholarly journals, academic conferences, disciplinary associations. As recently as a decade ago, the notion that cultural studies might secure a more stable position for itself within the university was still an open-ended question that could provoke heated debate. Today, however, cultural studies is sufficiently well established as a member of the disciplinary family that it's no longer news when fresh examples of cultural studies' institutionalization emerge: it's simply business as usual.

Lest I be misunderstood, I should emphasize that I don't want to see cultural studies abandon the spaces it has carved out for itself in the university, nor do I want to deny the very real intellectual and material gains that cultural studies' institutionalization has produced. There is certainly nothing noble or desirable about marginalization for its own sake, and cultural studies shouldn't retreat from the academy simply to avoid the taint of privilege that the institution brings. What concerns me is the sense that cultural studies' success within the university has come to define the outer limits of what the enterprise can and should be: that, having got into the institution, cultural studies is now content to do nothing more that reproduce itself.

In many respects, my argument here is an attempt to wrestle with a polemical question recently posed by Larry Grossberg: 'How did cultural studies get so $\mathrm{f}^{\star * * * * *}$ boring?' (Grossberg 2006: 8, ironically boring asterisks in the original). For Grossberg, 'boring' isn't an aesthetic or intellectual assessment as much as it's a political one: a pointed assessment of cultural studies' inability to intervene productively in the 'real world' contexts where it most hopes to make a difference: cultural studies' current centre of gravity 'pulls a lot of work into its orbits, posing questions, offering theories and validating methods that may not strengthen our engagement with or our ability to address questions to, the current conjuncture' (Grossberg
2006: 8). Up to this point in his argument, Grossberg's diagnosis of cultural studies' current shortcomings rings true, but then he takes an unusual detour:

That center, maintained increasingly by the institutional power of the academy and by the growing tendency to fold cultural studies back into disciplines, is built upon a certain limited ambiguity of the concept of culture, as cultural studies moved out from Williams' famous dichotomy: (1) culture as a limited set of signifying and textual activities sometimes referred to as aesthetic or expressive culture; and (2) culture as a whole way of life, as a material organization of practices.

(Grossberg 2006: 8)

From here, he goes on to offer an extended analysis of how cultural studies built itself around (and became trapped within) Williams' dichotomous model of culture, and of why it needs to find its way past the limitations of that model.

Where I want to pry apart Grossberg's diagnosis and pursue a different line of reasoning is at the point where he identifies - but then turns away from - 'the institutional power of the academy' and 'the growing tendency to fold cultural studies back into the disciplines' as the set of interlocking forces responsible for cultural studies' current crisis. Grossberg's analysis helps us to rethink the question of what cultural studies does, but the role of the university in cultural studies' current crisis suggests that we also need to rethink the interrelated questions of who does cultural studies and where they do so.

It's here that the second sense of my title comes into play, as I want to argue that cultural studies is not necessarily an academic enterprise at all The variable cocktail of intellectual and political work that we call 'cultural studies' can be - and already is being - mixed together with some regularity outside of the university, but cultural studies scholars have not been particularly adept at recognizing such work as a legitimate form of the enterprise. Cultural studies is ordinary: you should not have to go to the university to find it.

It is worth remembering that cultural studies did not originally arise in response to the needs and desires of the university, and that its early years within the university were far from comfortable. As noted above, Williams' musings on cultural studies' future dwell extensively on cultural studies' pre-Birmingham roots in post-Second World War workers' education programmes and the challenges those programmes deliberately posed to the British university system. Similarly, Stuart Hall describes the Centre for Contemporary Cultural Studies as 'the locus to which we retreated when that conversation in the open world could no longer be continued: it was politics by other means' (Hall 1990: 12, emphasis in original), and he has 
noted on multiple occasions that the more established departments at Birmingham spent years looking upon the Centre with open scorn - when they deigned to take notice of it at all. If cultural studies is now primarily an academic enterprise, it's not because it has always been such a thing, or because its earliest practitioners' highest priority was to move the fledgling project into the academic mainstream.

Perhaps the most direct way to rethink the current location of cultural studies is to look more closely at what cultural studies actually claims to do. Read the various meta-commentaries on cultural studies (excepting, perhaps, those problematic textbooks) and most of them will argue rightly - that there is no particular theory or method or object of study or political stance that is unique to the enterprise. Nor is there some simple litmus test one can use to determine the provenance of a given text or practice vis-à-vis cultural studies. The mere presence (or absence) of, say, post-colonial theory or ethnographic methods or Marxist politics can never guarantee that a particular project is (or isn't) an example of cultural studies. In essence, cultural studies encompasses four major spheres of activity:

(1) Theory: the construction of abstract models that attempt to explain the workings of culture, politics, the economy, the media, etc.

(2) Research: the production of new bodies of knowledge about culture, politics, the economy, the media, etc.

(3) Pedagogy: the public dissemination of all that theory and research, with the specific goal of helping 'ordinary people' come to a more robust understanding of the world around them.

(4) Action: the attempt to intervene in matters of public policy, opinion, and behaviour in order to promote social justice.

Significantly, the two spheres that cultural studies has been most heavily invested in - theory and research - are also the two that are most readily articulated to the institutional practices of the university. Meanwhile, the two spheres where cultural studies has been less successful - pedagogy and action - are also the two where various non-academic endeavours that deserve to be (but typically have not been) recognized as cultural studies have often outperformed their scholarly counterparts. Let me offer a few brief comments about each of these four spheres of activity and their respective relationship to cultural studies, both inside and outside the university.

\section{Theory}

Cultural studies scholars typically reserve the word 'theory' for a particular genre of prose that describes an abstract model of how the world (or some significant piece of it) works. More specifically, this brand of theory is primarily crafted by a relatively narrow range of academics: philosophers and other humanities types are welcome here; but most social and behavioural scientists need not bother applying. Abstract maps of culture and society, however, are already an integral part of most people's daily lives, and so theory isn't the exclusive province of professional scholars. Michael Bérubé poses the question this way:

Is gender performativity something concocted in an academic laboratory, or is it something you can see in Paris Is Burning - or down the street? ... Is it discourse-besotted metahistorians or campaign managers who know that representations are social facts? Do we have to introduce publishers, futures traders and real estate agents to the idea that there's no such thing as 'intrinsic' merit, that merit is a social phenomenon? ... I don't think so. I think, to put it plain, that all these constituencies are doing the stuff we talk about in a different voice. One of the primary reasons 'cultural studies' names such a volatile enterprise is that it finds itself examining populations that have their own descriptive languages for themselves, which don't always mesh very well with de Certeau or Laclau and Mouffe but which serve the purposes of enunciating group identities, practices and self-definitions.

(Bérubé 1994: 166)

To be sure, not all maps of the world are equally accurate or valuable, and so we can - and should - still draw qualitative distinctions between different theories. And, when it comes down to actual cases, we may find academic theory to be more valuable than 'quotidian' theory. This, however, is an empirical question to be tested in the context of specific projects, rather than an axiom we should simply accept in advance. The value of theory for cultural studies, after all, is to provide us with better maps and tools for the political projects that (allegedly) motivate our work. Given that mandate, one of the advantages that 'quotidian' theory often has over academic theory is that it tends to arise very much in the service of 'real world' issues and problems, rather than as a self-justifying phenomenon. 'Ordinary people' theorize their lives and their world all the time (culture, after all, is ordinary), and they often do so in more grounded ways than academics do. And so we should not dismiss those maps of the world as unworthy simply because they've been produced by people who lack graduate degrees.

\section{Research}

In the context of academic cultural studies, 'research' typically refers to scholarship that is necessarily informed by some form of disciplinarity that is, a rigorous adherence to a fixed range of established conventions and methods - even while cultural studies loudly (if often disingenuously) 
distances itself from the very notion of academic disciplines. As such, what typically counts as legitimate cultural studies research are the sorts of investigative practice already valorized by traditional scholarly fields, while other investigative practices - particularly those associated with journalism or the arts - are either dismissed out of hand or, at most, welcomed as the sort of 'raw' primary material that can serve as the object for 'real' cultural studies research. Even in those instances when cultural studies scholars stretch beyond their home disciplines, they typically only do so to engage with other disciplines: that is, they produce interdisciplinary, rather than extradisciplinary or even nondisciplinary, research.

As Stuart Hall notes, however, the main reason why cultural studies practitioners should do research is so that we can 'know more than the traditional intellectuals do: really know, not just pretend to know, not just to have the facility of knowledge, but to know deeply and profoundly' (Hall 1992: 281). That sort of 'deep and profound' knowledge, however, will not always be ours if we assume in advance that the only knowledge worth having comes from the university. As is the case with theory, the production of knowledge is something that happens outside the university as much as it does within it, and any good journalist or policymaker or historical novelist or political activist or documentary filmmaker can - and should - do good research as a routine part of their ordinary business.

\section{Pedagogy}

Insofar as 'pedagogy' typically refers to classroom-based instruction, it would seem to be the most academic sphere of activity under discussion here, and so it may seem odd to place it on the non-academic side of the fence. Pedagogy, however, is an activity that universities honour much more on paper than in practice. While campus administrators often speak reverently about the value of good teaching, they rarely match those noble words with policies that demonstrate a meaningful commitment to what happens in actual classrooms. Faculty members may be denied tenure because their teaching is weak, but they'll rarely (if ever) be granted tenure solely because their teaching is superb. And academic cultural studies has embraced this philosophy all too fully. To be sure, cultural studies scholars often invoke critical pedagogy as a worthy set of educational practices, and I'm willing to believe that many of us actively work to embody those values in our classrooms. Even within cultural studies' circles, however, we tend to celebrate research and theory much more than we do teaching.

More crucially, I would argue that the sphere of pedagogy extends well beyond the sort of formal teaching that happens in college and university classrooms: that it encompasses a vast range of communicative practices from op-ed columns to documentaries, from public art installations to blogs - where a diverse range of intellectuals (broadly defined) attempt to share the knowledge they've produced with a broader public. And, in this sense of the term, pedagogy is an arena where non-academics have generally been much more effective than professional scholars.

\section{Action}

Cary Nelson has taken Jan Radway to task for her claim that 'the definition of cultural studies should be expanded to include a whole range of political activities' (Nelson 1996: 278). For Nelson, this notion is so absurd that he can't believe that any reputable scholar would utter it. 'It should not be necessary to say this,' he writes, 'but apparently it is: Cultural studies is a set of writing practices; it is a discursive, analytic, interpretive tradition' (ibid.: 278).

Insofar as there's much more to doing cultural studies than being a good activist, Nelson is right to argue that 'political action and cultural studies are not interchangeable' (ibid.: 278). One shouldn't get to claim that one does cultural studies simply because one shows up at progressive demonstrations or volunteers for leftist causes. Where Nelson's argument runs aground, though, is in his insistence that cultural studies is merely just 'a set of writing practices.' And though it should not be necessary to say this, apparently it is: the distinction that Nelson makes between 'political activities' and 'writing practices' is not just false, it's precisely the sort of simplistic either/or choice between mythical opposites that cultural studies has struggled against for half a century. Put plainly, we don't have to choose between 'writing practices' and 'political activities', as if the two were mutually exclusive, or as if this thing we call 'cultural studies' were too cramped and inflexible to accommodate worthy examples from both categories.

By way of comparison, other noteworthy enterprises manage to embrace both theory and action simultaneously, and it's not a coincidence that there's significant intellectual and political overlap between many of those endeavours and cultural studies. As is the case with 'feminist' and 'Marxist', there's no necessary reason why 'cultural studies' can't - and shouldn't - be more broadly used to modify 'theory' and 'practice', 'scholarship' and 'politics', 'research' and 'activism'. Many cultural studies scholars do extensive (and valuable) activist work of one sort or another. And, presumably, much of the theory and research that they gladly call 'cultural studies' informs such work in significant ways. And yet, curiously, the 'cultural studies' label rarely travels with them when they leave do that work, even though it could. And should.

I give myself three wishes, even if I have nothing nearly as majestic as 'the swans I have just been watching on the lake' (Williams [1958] 1989b: 14) to wish upon. I ask for things that are part of the ethos of our cultural studies tradition. I ask that we may be strong and human enough to realize them. And I ask, naturally, in my own fields of interest. 
My first wish is for cultural studies scholars, individually and collectively, to do a better job of reshaping the university than the university has done to reshape cultural studies. This is not to deny the small victories that cultural studies can already claim on this front, but the fact remains that cultural studies' 'infiltration' of academia has not revolutionized the university nearly as much as it has transformed (and diluted) cultural studies. Bill Readings' assessment of cultural studies as the ideal quasi-discipline for the 'university of excellence' (1996) is, lamentably, all too accurate. Transforming the university, of course, is much easier said than done, especially given that cultural studies scholars are not always eager (or invited) to move into the sorts of administrative position where such changes might most readily be effected. And I have no illusions that cultural studies is singlehandedly capable of reversing the tide of political, economic and cultural forces that have led to the increasing corporatization of the university.

I continue to believe, however, that cultural studies can and should still serve as the proverbial fly in the university's ointment, and that it's important for cultural studies academics to remain vigilant about holding the institution's feet to the fire as circumstances warrant. As Radway has put it:

The reason I continue to stay in the academy is that I don't think we can simply afford to walk out ... We can't simply give up on the academy. If we do, there are other people ready to make it an even purer space of domination.

(Radway 1992: 529)

My second wish is that cultural studies practitioners working across a broad spectrum of institutional spaces, both on and off campus, learn to recognize - and make common cause - with one another. Perhaps most obviously, cultural studies scholars need to be better about reaching out to kindred spirits who don't normally travel in academic circles. As much as cultural studies scholars like to celebrate Gramsci's notion of the 'organic intellectual,' when we actually encounter such figures, we seem reluctant to embrace them as fellow practitioners of cultural studies - unless, of course, they cross over into 'our' world and spend several years immersed in the peculiar pain of pursuing a graduate degree or two.

And this strikes me as a failure of nerve and imagination that we need to get beyond. The university continues to matter to cultural studies because it affords people a measure of freedom to produce sophisticated combinations of rigorous intellectual and political work, but it's by no means the only place where such work is possible. In certain contexts, it's not even necessarily the most valuable or effective place for such work. But if we're unable to imagine (much less locate, or embrace, or learn from) people who actually do cultural studies outside of university settings, then Williams' fear that cultural studies would become just another career option for bourgeois academic professionals may already be true.

Given my argument to this point, my final wish may be predictable: that cultural studies takes the task of reinventing and extending itself much more seriously than it has. This means more than just broadening the range of disciplines that intersect with cultural studies' orbits, more than just building new theoretical models to guide our scholarship, and more than just finding new research questions to meet the demands of a changing world. These are all valuable tasks, and a cultural studies worthy of the name will not shirk from them. But, on their own, none of them is likely to shake cultural studies out of its current doldrums, as none of them is likely to do much to reconfigure cultural studies' current relationship to the university in any significant fashion.

Larry Grossberg (2006) refers to Gramsci's notion that the first job of the intellectual is to know more than 'the other side', and he suggests that cultural studies hasn't done a very good job of living up to that ideal. Insofar as those of us who do cultural studies in academic settings could be better about producing the sort of rigorous scholarship and richly contextualized knowledge that allows us to make crucial interventions in public debates, I would agree with Grossberg's criticism.

But I actually think that cultural studies' real failing has more to do with the second half of Gramsci's comments: that is, not just knowing more than the other side, but communicating that knowledge effectively to a broader public. The professional scholars who occupy the centre of cultural studies, after all, already spend much of our time and energy engaged in the production of knowledge. And while it's fine to urge cultural studies to produce better knowledge than it has, if we've failed to live up to this aspect of Gramsci's imperative, it's not because we've left the business of trying to produce better knowledge off our agendas.

So while I, too, hope that cultural studies can know more than the other side, I think the need to improve how - and how far - we spread that knowledge is more important and more pressing. Of course, this is by no means an easy process and it's certainly not reducible to a sort of missionary project where we simply deliver our pre-packaged insights to a public waiting for us to tell them the truth about their lives. It is, instead, a process that will require us to listen as well as (and probably better than) we speak, and to do so with publics with whom we don't normally share the fruits of our intellectual labours. Here, I would want to echo 'Culture is ordinary' quite explicitly:

We should not seek to extend a ready-made [cultural studies] to the benighted masses. We should accept, frankly, that if we extend our [cultural studies] we shall change it: some that is offered will be rejected, other parts will be radically criticized. And this is as it should be, 
for our [studies], now, are in no condition to go down to eternity unchallenged. There is much fine work; there is also shoddy work, and work based on values that will find no acceptance if they ever come out into the full light. To take our [studies] to new audiences is to be quite certain that in many respects those studies will be changed. I, for one, do not fear this.

(Williams [1958] 1989b: 16)

\section{Acknowledgments}

I would like to thank Margaret Werry, Greg Seigworth, and Jillian Clements for their helpful feedback on earlier drafts of this chapter.

\section{Raymond Williams: reading novels as knowable communities}

Ana Clara Birrento

His work is still 'in time for us', Stephen Connor wrote in 1998 about Raymond Williams. In fact, twenty years after his death, Williams' intellectual legacy is, indeed, still in time for us. Williams remains an influential figure and a source of inspiration for any theorist or practitioner of cultural studies, into whose grammar he engraved a set of fundamental concepts and relevant analytical tools. In the perplexity of understanding (Inglis 1993), Williams reflected, revised and developed his critical positions about the nature of culture, the politics of literature and social relations, rehearsing them to find new definitions which enable us to know the modes of

Out of the body of knowledge and critical intervention, two core legacies have engaged my attention: the concepts of 'structure of feeling' and 'knowable community'. ' The alliance of these methodological and analytical tools helps us to apprehend the active processes involved in the social and cultural changes and to clarify the textures of historical experience. As cultural categories, they have allowed us to reassess and to recontextualize novels as cultural constructions, putting into perspective what have been two torn halves: the great tradition of high, institutional, canonical culture; and the common, exterior culture, product of a democratization process of culture and society, a process which has connected human beings and the social, political and economic structures of the great arch of history.

Williams brought together what modern thought has separated in the relation between culture and society. The study of the literature and the analysis of the culture of a period are recurrent in Williams' critical work. His use of literary texts to exemplify the concept of 'knowable community', as well as the concept of 'structure of feeling' is one of his achievements. The latter allows Williams to examine the interrelation between areas of individual experience and social experience, allowing him also to examine interrelations between public and private processes and between historical formations and social structures, turning these active and communicable
(John and Lizzie Eldridge 1994). 


\section{About Raymond Williams}

\section{Edited by}

Monika Seidl, Roman Horak, and Lawrence Grossberg

\footnotetext{
Routledge

Taylor \& Francis Croup

LONDON AND NEW YORK

2010
} 